\title{
Internally Incentivized Interdisciplinarity: Organizational Restructuring of Research and Emerging Tensions
}

\author{
Mikko Salmela $^{1,2}$ (i) $\cdot{\text { Miles } \operatorname{MacLeod}^{3}(\mathbb{D})}$ Johan Munck af Rosenschöld $^{4}(\mathbb{D}$
}

Accepted: 16 December 2020 / Published online: 17 February 2021

(C) The Author(s) 2021

\begin{abstract}
Interdisciplinarity is widely considered necessary to solving many contemporary problems, and new funding structures and instruments have been created to encourage interdisciplinary research at universities. In this article, we study a small technical university specializing in green technology which implemented a strategy aimed at promoting and developing interdisciplinary collaboration. It did so by reallocating its internal research funds for at least five years to "research platforms" that required researchers from at least two of the three schools within the university to participate. Using data from semi-structured interviews from researchers in three of these platforms, we identify specific tensions that the strategy has generated in this case: (1) in the allocation of platform resources, (2) in the division of labor and disciplinary relations, (3) in choices over scientific output and academic careers. We further show how the particular platform format exacerbates the identified tensions in our case. We suggest that certain features of the current platform policy incentivize shallow interdisciplinary interactions, highlighting potential limits on the value of attempting to push for interdisciplinarity through internal funding.
\end{abstract}

Keywords Interdisciplinarity · Tensions · Funding structures · University · Platform · Incentives

Mikko Salmela

mikko.salmela@helsinki.fi

1 TINT, Practical Philosophy, University of Helsinki, Helsinki, Finland

2 Center for Subjectivity Research, University of Copenhagen, Copenhagen, Denmark

3 Department of Philosophy, University of Twente, Enschede, The Netherlands

4 TINT, Practical Philosophy, Helsinki Institute of Sustainability Science (HELSUS), University of Helsinki, Helsinki, Finland 


\section{Introduction}

Interdisciplinarity is widely considered necessary to solving many contemporary problems, such as those related to climate change and sustainability. University administrators are sensitive to these goals as well as to the shifting funding structures put in place by national and international funding regimes to encourage them (Jacobs and Frickel 2009; Wright and Ville 2017). In this article, we consider what happens when a small technical university (here labeled "BizTech") implements a university-wide policy aimed at strongly incentivizing cross-disciplinary collaboration amongst its schools. This policy, which we call the "platform strategy," has reallocated all internal research funds for at least 5 years to platforms incorporating researchers from at least two of the three schools within the university.

In this article, we focus on the use of such a platform strategy as a means for promoting and developing interdisciplinary collaboration. Existing studies of interdisciplinarity emphasize that interdisciplinary collaboration is often difficult by virtue of various tensions, including epistemic, structural and emotional tensions, or conflicts that collaborators meet when they attempt to engage in it (e.g. Mansilla et al. 2016; Parker and Crona 2012; Turner et al. 2015). The aim of the article is to study how and to what degree such tensions manifest themselves when interdisciplinarity is incentivized among university colleagues by a strategy of creating a small number of interdisciplinary research platforms. The platform strategy at BizTech itself is similar to other novel approaches currently being fashioned by university administrators to internally adapt research within their universities (see e.g. Lindvig and Hillersdal 2019). Previous studies have also explored the influence of organizational characteristics of university centers on interdisciplinary collaboration (e.g. Boardman and Corley 2008; Mäkinen et al. 2020). The platforms at BizTech present an interesting case, as they are neither projects nor more permanent research centers. Studying these platforms provides us with novel and important insights into the attempts of universities to promote interdisciplinarity within its faculties and schools. Using data from three platforms at BizTech, we show that certain organizational characteristics of the platform policy generate specific interdisciplinary tensions. We identify the characteristics of these tensions, and explore the extent to which the current platform policy serves to increase the tensions often inhibiting interdisciplinarity despite its professed goal of increasing interdisciplinary collaboration. Our article will thus provide guidance to those seeking to design and implement such policies as means of promoting interdisciplinary collaboration in the future.

\section{Conceptual Framework}

\section{Promoting Interdisciplinarity in Universities}

Interdisciplinary research has gained an increasingly strong position in contemporary research policy. This can partly be explained by growing interest in complex 
sustainability problems which cross existing disciplinary boundaries within academia and encourage integration of various sectors in society (e.g. Buanes and Jentoft 2009; Lyall et al. 2013; Pohl et al. 2017). Despite the spread of the concept, interdisciplinarity is notoriously difficult to define and various definitions and typologies have been put forward (see e.g. Huutoniemi et al. 2009). The predominant view among scholars and funding agencies is that for a cross-border interaction to count as interdisciplinary, there needs to be some kind of epistemic integration between the participating disciplines, to the extent that novel approaches and practices are produced. The contemporary methods of disciplines are thought insufficient to solving the current complex problems which motivate interdisciplinarity resulting in "a more profound scientific understanding or more comprehensive explanations of the phenomena under study" (Huutoniemi et al. 2009: 85). Further, although any cross-border interaction including exchange or transfer of knowledge, methods, problems etc. (see Grüne-Yanoff 2016), either by individual researchers or collaborative research teams, can be integrative and therefore qualify as interdisciplinary, interdisciplinary research is usually understood as a collaborative interaction, requiring engagement of individuals from different disciplines. A potential rationalization for this limitation is that researchers see interpersonal engagement and negotiation as necessary to the kinds of breaking down of disciplinary norms and standards needed for effective integration.

These epistemic goals set up certain expectations with respect to interdisciplinarity. Collaborations which fail integrative goals but nonetheless involve cross-border interactions and exchanges are usually labelled "multidisciplinary." Multidisciplinarity is thought typical in instrumentally oriented research with extra-academic aims, such as solving social problems or developing commercial products. However, it is widely thought that much research that happens under the label "interdisciplinary" is more multidisciplinary, thus frustrating the goals of funders and others who think that integrative interdisciplinarity is imperative (MacLeod and Nagatsu 2018). In multidisciplinary projects, researchers typically break up problem tasks into subtasks they can fulfill largely independently. Researchers can then follow epistemic standards and practices of their disciplines without needing to rethink and modify them. How to make researchers engage in "genuine" or "strong" integrative interdisciplinary collaboration remains a central challenge, one for which there seems ample room for innovative approaches and incentives.

Universities have responded to the perceived need for interdisciplinarity in various ways. According to a survey sent out to academic institutions, the most common initiatives for promoting interdisciplinary collaborations at universities include creating an organizational setting that is conducive to collaboration, incentivizing faculty through modifying policies to encourage interdisciplinary research, and offering seed money for interdisciplinary projects (National Academy of Sciences 2005). Universities have created interdisciplinary programs organized as freestanding units or as virtual programs (Holley 2017), or have subordinated existing faculties and departments. Universities have also established interdisciplinary laboratories (Choi and Shields 2015) and research centers involving scientists from different disciplines and extra-academic actors (e.g. Boardman and Bozeman 2007; Brint 2005; Mäkinen et al. 2020; Parker and Crona 2012; Townsend et al. 2015). An example is the 
increasing number of research centers focusing on sustainability science that are created to spur cooperation between academic disciplines and extra-academic actors (Soini et al. 2018). The idea behind the creation of interdisciplinary centers is to "provide a legitimate space for scholars interested in exploring knowledge creation beyond the boundaries of their disciplines" (Mäkinen et al. 2020: 72).

Earlier studies of internal university-based initiatives for stimulating collaboration across disciplines have focused on exploring the influence of institutional and organizational design of research centers on collaboration. For example, in their quantitative study, Boardman and Corley (2008) assessed how the size of the center, the degree of multidisciplinarity of center members, and the number of ties to industry and national government-sponsored center programs influenced the time that scholars spent on collaborating with colleagues from other disciplines. Their findings suggest that belonging to a research center with many ties to industry and other federal centers increases collaboration within the same university, but not outside the university. In their qualitative study of three interdisciplinary centers, Mäkinen et al. (2020) found three features that were beneficial for interdisciplinary cooperation: the alignment of the mission of the center and the interests of the researcher, the architecture of the center in allowing for informal interaction and knowledge exchange between researchers, and the leadership of the center.

Although previous research has studied different innovations which universities have developed to accommodate interdisciplinarity, the focus of research has been on more permanent organizational units, such as research centers on the one hand, and on temporary research projects on the other. As we explain below, the case we focus on is neither permanent nor operating at the level of projects. Rather, it aims at generating a temporary middle-level form of organization. Such strategies are of increasing interest as relatively new strategies for generating interdisciplinarity. Lindvig and Hillersdal (2019) studied the creation of a similar new interdisciplinary program at the University of Copenhagen. They report that unclear incentives, motives, and assessment criteria of the program hindered the promotion of interdisciplinary collaboration and instead reproduced existing disciplinary structures at the university. Some of our findings replicate theirs, particularly the consequences of not setting explicit standards for interdisciplinarity. However, one important difference in our case from the Copenhagen case is that the BizTech platform strategy directly takes control of internal university-level research funding, and allocates it fully to the platforms creating an imperative to join platforms. Thus the platform strategy appears a stronger attempt to initiate cross-school collaboration, which raises the question whether greater imperatives have a stronger outcome. As such, the strategy presents an interesting and innovative case for studying the role of organizational design in either promoting or inhibiting interdisciplinary collaboration.

\section{Tensions in Interdisciplinary Collaboration}

Our analysis of the platform strategy here draws on a number of background studies on the concept of "tension" used to study interdisciplinary relationships (e.g. Hackett 2005; Mansilla et al. 2016; Parker and Crona 2012; Rhoten and Parker 2004; Turner 
et al. 2015). Turner et al. understand "essential tensions" in interdisciplinary research as "necessary and persistent contradictory imperatives in the scientific process" (Turner et al. 2015: 649). The notion of "essential tension" has the connotation of being fundamental and in some sense pervasive and unavoidable. Borrowing from Hackett (2005), Turner et al. postulate that these tensions strongly affect the fates of researchers involved. We argue, however, that not all tensions arising in interdisciplinary contexts have such force or necessity. There is thus need for a less strict and more context-sensitive notion of tensions which affect researchers and play a part in how they experience interdisciplinary collaboration (or calls for it), which reflect the different positions and situations of individuals and groups. For our purposes, then, we understand a tension as a relational concept, which signifies a conflict between two or more sets of expectations, interests, values or goals of researchers or their groups. Such tensions are context-dependent and might only be felt in certain contexts or by particular agents depending on their constellations of interests and situations. Such tensions are often experienced as perceived or potential costs in pursuing one set of interests or goals rather than another. Our goal here is to analyze the platform strategy in terms of the types of tensions it has generated among particular researchers or research groups in respect of the condition to collaborate across schools.

This being said, Turner et al.'s classification of tensions in interdisciplinary interaction-epistemic, structural, and emotional—remains informative for our purposes. Epistemic tensions cover conflicts between sets of disciplinary epistemic standards and values, and what counts as reliable or meaningful research question, method, or result from the perspective of each discipline (Andersen 2016; Mansilla et al. 2016; Turner et al. 2015; Kuhn 1970). Structural tensions are conflicts in incentives arising from the academic reward and funding structure, given disciplines generally favor disciplinary over interdisciplinary merits in promotion and tenure evaluation (Müller and Kaltenbrunner 2019; Wright and Ville 2017). Both structural and epistemic tensions are likely to give rise to emotional tensions whenever the relative comfort and surety of identity and status that comes with a discipline comes into conflict with the demands of interacting across disciplinary boundaries (Becher and Trowler 2001; Collins 1998; Mansilla et al. 2016; Parker and Hackett 2012; Salmela and Mäki 2018). Tensions of this kind may manifest as feelings of inadequacy, incompetence, or discomfort as one moves beyond one's disciplinary comfort zone, or as feelings of being disrespected and mistrusted by others due to, for instance, the asymmetric valuation of different epistemological frameworks that often associate with financial and status asymmetries between disciplines (Callard and Fitzgerald 2016; Mansilla et al. 2016; Turner et al. 2015). We use this broader concept of tension and this framework of specific tensions in our study of the platform strategy.

\section{Methods and Materials}

\section{The BizTech Strategy}

BizTech is a small regional technical university located in a Nordic country and it specializes in the production of green technology. In 2015, the university adopted 
a package of policies, whose goals included the promotion of interdisciplinary research for solving complex problems relating to sustainability, but also making the university more competitive in the pursuit of European funding. The scarcity of funding and the need to compete for that funding is a dominant problem for many small and regional universities in Europe. In addition, a drive at the national level to specialize among the nation's universities and to concentrate expertise on just a limited set of research topics was identified by BizTech management as an imperative.

The research funding strategy was formulated through a fundamental reorganization of funding incentives. All internal research funding from 2015 to 2020 was cancelled. Instead, the staff were asked to reapply for the funding for specific research "platforms". ${ }^{1}$ What a platform should look like was not tightly specified. However, the application form strongly resembled a standard application for a consortiumbased grant, and in response, the platform applications generally took a traditional "work package" structure. The hope was that the platform would serve not just as a platform for research, but as a platform for applications of external funding which would scale up the initial platforms. The applicants were asked to define a specific problem or problem solving goal, and to explain how the proposed research would help carry out the BizTech's strategic goals for research. Applicants were also asked to list external collaborators who could co-fund potential grant applications and to describe the significance of the research platform for education, researcher training and promotion of research careers. Importantly for a platform to be awarded funding, it needed to involve researchers from at least two of its three schools in interdisciplinary collaboration. Platform applications were reviewed internationally and the best were allocated funding for 5 years in terms of their academic quality, in terms of their interdisciplinary qualities, and how well they met the strategy of the university, formulated in terms of grand challenge-type of research questions.

The process of finding more specific topics upon which to collaborate and preparing platforms was left to the university's academic staff. 12 plans of intent were first reviewed internally at BizTech, with 9 invited to submit a full proposal for an international review, after which 6 were selected, with some dispute over whether even all of those satisfied the university's objectives. Each platform receives from BizTech an annual amount of 350-400,000€ that it can use to hire postdocs, graduate students, or a research coordinator, but not to the salaries of senior researchers or the PI. Besides this seed funding from the university, the units are expected to raise additional funding from external sources, such as central national funding agencies, Horizon2020, and other EU funds, among others. There was an internal mid-term evaluation of the platforms by the BizTech rectorate in 2018 that all platforms passed, although two of them with minor criticism. There has not yet been a final evaluation, as the platforms are running till the end of 2020.

\footnotetext{
1 It is worth mentioning here that we are aware of the many uses of the term "platform" in various scientific fields, but we use the concept to refer only to the new temporary mid-level organizational units that were created at BizTech. The choice of using the concept was driven by the fact that the university itself adopted the term to describe the units.
} 


\section{Presentation of Research Platforms}

In this article we focus on the three platforms we have most closely investigated and followed. The selection of platforms was based on the following considerations. First, we selected platforms that had not received external research funding prior to the initiation of the platform. By doing this, we gained a better understanding of the influence of the new platform structure on interdisciplinary collaboration rather than relying on pre-existing resources. Second, we selected platforms that were structurally different to allow for variation across the cases. This allows us to further investigate the tensions that arise in the different platforms.

Platform A was created by establishing novel collaborations across the schools of BizTech as well as relying on a number of already established relationships. The platform was devised in an open manner and the PI encouraged various professors and research groups to join. The platform initially engaged 19 research groups working in the field of resource efficiency at BizTech who later on have been mobilized on an ad hoc basis in various constellations in individual research projects and funding applications. The initial phase of the platform was challenging, but the platform was later able to secure a sizeable EU project, which was well received in the midterm evaluation of the platform. The platform was also praised for its efforts to create novel collaborations between research groups. However, due to its large size and the limited funds available, the platform is constantly dealing with the challenge of activating and integrating the various research groups and persons attached to the platform. In an attempt to address this challenge, the platform has dedicated a significant amount of effort towards connecting the platform's research groups in external research project applications.

Platform B arose out of established collaborations amongst engineers aiming at the development of realistic simulations of construction vehicles, which could replicate the operating experience for users, and this research had already allowed the engineers to develop numerous corporate relations. Business researchers joined to assist in the design of the simulation technology by providing better insights into the needs of corporate customers. This platform has been extremely successful in acquiring funding, obtaining almost immediately the equivalent amount of funding as the platform funding from a national "business research" funding scheme. In the following years at least three other projects have been acquired through platform collaborations. Participants in this platform such as the PI and business professors report a satisfactory and mutually rewarding collaboration, resulting from the acquisition of project funds, and also from joint publications. The groups have worked to maintain close bonds through frequent platform meetings but also joint presentation and education events, and by placing their $\mathrm{PhD}$ students together in shared spaces.

Platform $\mathrm{C}$ was initiated by two senior professors from the school of energy systems who recruited two other professors, one in industrial management and engineering and another in sustainability science, to join. This platform studies discrepancies between measured and reported emissions of greenhouse gases from various domains such as industries, cities, and traffic as well as the transport of CO2 emissions from inland waters to the atmosphere. The platform operates mainly through the leader who has bilateral collaborations with the other work package leaders. The 
Table 1 List of data used in this article

\begin{tabular}{lc}
\hline Interviews & \\
\hline Informants & $\begin{array}{l}\text { \# of } \\
\text { interviews } \\
\text { conducted }\end{array}$ \\
\hline BizTech rectorate & 5 \\
Platform PIs & 9 \\
Platform coordinators & 4 \\
Faculty members (lecturers and professors) & 14 \\
Postdocs and PhD students & 8 \\
Supporting materials & $\mathbf{n}$ \\
Platform applications, mid-term evaluations of the selected plat- \\
$\quad$ forms, and university strategy documents
\end{tabular}

whole group has never met and group members do not necessarily have more than a vague idea of what happens in other work packages as the research question of the platform is formulated in a such way that each team is able to operate independently. The platform has not received external funding as a group so far, although some work package leaders have succeeded in raising external funding with their own partners. The platform was criticized in the mid-term evaluation for lack of collaboration in research, and it remains to be seen how it responds to this criticism.

It is noteworthy that the platforms in question are organized in different ways. Platform A is organized akin to a loosely defined network, which is mobilized in an ad hoc fashion depending on what types of scientific expertise is needed for the research task or project currently underway or funding application in preparation. Platforms B and C are organized in a different way. Although they engage multiple professors and research groups in novel constellations, they resemble research consortia centered around a single research project. Despite these differences, the most important common characteristic of all the platforms is that they are required to engage researchers from the same university, which stands in contrast to research consortia in general, where the participants are chosen based on common research interests across universities.

\section{Methods}

We have followed the development of the platforms at BizTech from 2015 to 2020 as part of an ongoing research project. During the project we conducted semistructured interviews with platform PIs, coordinators, professors, senior and junior researchers from three platforms, and the rectorate $(n=40)$ (see Table 1). The more senior interviewees were selected based on the centrality of their formal position in the platforms and the university more broadly as well as on snowball sampling of more junior informants, as they were more difficult to identify from available sources. The interviews were conducted between 2015 and 2019 and the length of the interviews varied between 30 and 90 minutes. The interviews were conducted 
in English $(n=33)$ and in native language $(n=7)$. The reasons for conducting the interviews in English were two-fold: 1) a number of informants did not speak the native language and 2) many interviews were conducted by non-native researchers. We believe conducting the interviews in English did not present methodological challenges, as the informants had great proficiency in English and it is the de facto working language of the informants. Quotes from the interviews are verbatim transcriptions that have been only mildly edited by the authors to eliminate "noise" (coughs, repetitions, etc.) and therefore reflect the actual words of the informants. Some informants were interviewed multiple times during the data collection phase. While our main focus is on analyzing the interview data, we have also collected and analyzed the platform applications, mid-term evaluation documents of the platforms from 2018, and university strategy documents to support the analysis of the interview data.

By conducting semi-structured interviews, we were able to obtain valuable insights into the workings of the platform. During the interviews, the informants were asked questions related to the platform they are involved in, their experiences of the work at the platform, and their work more generally. For the interviews, we constructed interview guides around a set of themes we were interested in discussing with the informants. The informants were also given ample opportunities to elaborate on issues emerging during the interview that they felt most relevant to them. The data was analyzed using qualitative content analysis (QCA). We used QCA to analyze both explicit meaning and interpretation of more implicit content and themes (see e.g. Hsieh and Shannon 2005) pertaining to tensions arising in interdisciplinary collaborations. To study how the informants talked about the challenges they face when working in the platforms and how they describe this work compared to their ordinary work tasks, we applied an inductive approach with open coding through which categories were created. The interview transcripts were read multiple times to ensure that we were able to identify all relevant data. Subsequently, based on the prevalence of categories and in-depth discussions among the co-authors, we developed broader themes to extract the more implicit meanings in our data. During the analysis, we refined the categories and themes continuously and compared them especially with the three types of interdisciplinary tensions identified by Turner et al. (2015) to build on and extend existing work. The categories and themes identified in this article are therefore a result of an interplay between our inductive approach and the existing literature.

\section{Results}

While there are many interesting aspects to how these platforms have panned out, our principal focus is on the specific tensions-particularly epistemic, emotional and structural tensions related to interdisciplinarity - such a strategy gives rise to. We conclude this section by discussing the role of the platform format in influencing the identified tensions in our case. The quotes included in the following sections are used to illustrate how the tensions are played out in our empirical setting more concretely. 


\section{Tensions Arising from the Allocation of Platform Resources}

One of the tensions identified in our data is the contestation of the allocation of funding within the platforms. This structural tension concerns the expected benefits of platform collaboration. On the one hand, there is the expected benefit of collaboration from the perspective of all groups on a platform; on the other hand, there is the expected benefit of participating in such collaboration from an individual group's or professor's perspective. Collaboration holds promise of greater expected benefit in a longer term than working with one's own group. However, this benefit requires the collaboration of others, which makes the achievement of this benefit less probable than the smaller short-term benefit of working within one's group. As the allocation of platform resources is an important issue to the participants, it is also a source of emotional tensions relating to perceived benefit or loss from collaboration. As will be shown, the strength of these tensions depends on the size of the platform.

As organizational entities, the platforms extend beyond individual research projects. In more traditional project-based interdisciplinary collaborations there are more clearly defined roles with an assigned PI, who often is a professor or senior researcher, postdocs and doctoral researchers that together form a research group. The research group is more independent, and can itself decide on the research aims, goals, methodology etc. In a research project, the division of resources is also clearer (see e.g. Franssen et al. 2018), such that all participants can expect to "get their own share." In contrast, in the platforms, the focus is on forming collaborative networks between professors and their groups within BizTech that seek to utilize their synergies in raising external funding with the help of the BizTech platform "seed money."

A main issue from the perspective of platform resources is thus how the platform money is distributed across the professors and research groups. This issue played out differently in the selected platforms, but in some platforms gave rise to explicit tensions. For Platform A, which involves a great number of professors and research groups across BizTech, these structural tensions are illustrated in the following quote that also highlights emotional tensions relating to allocation of platform resources:

It's really a difficult thing for professors that they didn't get what they wanted, but they had to think about the whole 19 groups. And also they may be understood that $\mathrm{OK}$, this is the way we have to do this. But still, some of them were really angry with the decision, because they had waited that they will get money for their big thoughts. And now they are not so able to collaborate. (Platform participant, emphasis added)

Here, the participant stresses the need to cater for the whole group of professors and research groups at the expense of focusing on individual research groups. The focus is thus on using the funding to realize the broader research goals of the platform as a whole, which in this case means that funding will need to be strategically allocated among the platform participants with the platform goals in mind. This way of dividing existing resources was not welcomed by all participants involved, as illustrated by the following: 
It's not easy to say why this is not functioning as well as it could. But, maybe the main reason is that we don't exactly see what is the added value from the platform currently to our individual research groups. Somehow it fails to pull things together and to make things easier for us. I guess that this was one of the ideas of the platform, that it would facilitate the fundraising and everything and thus make everything easier, but it doesn't currently do it. But, yes, it would be very good if we could get this thing running better. (Platform participant, emphasis added)

To this participant, the platform fails to deliver on the expectation that getting involved in the platform would improve their chances of obtaining resources. The participant also questions the purpose of the platform, as the person cannot see how the platform can benefit individual research groups. Compared to the previous quote, the reference to the research groups in this quote highlights a contrasting view of how the platform should divide the available resources among participating members. These contrasting viewpoints highlight the obstacles of integrating a large number of research groups into a single interdisciplinary platform with limited resources and the difficulty for individual researchers to navigate between the expectations of the platform and research groups. As will be discussed later on, as the logic of the BizTech platforms challenge the traditional format of organizing research, the question of "who gets what" becomes central.

However, not all platform participants were discussing the role of resources in an equally negative manner. Especially with regards to the platforms with fewer number of participating research groups, the challenges of including and committing researchers to the platform appeared to be smaller. When there are fewer partners with whom you have to share the limited resources of the platform, each gets their "own share" of the platform funding provided by BizTech. For example, with regards to Platform B the following quote illustrates well the situation:

[The atmosphere in the platform] is very good...Mainly because it's just the low number of professors involved. So we could actually give some serious financial help to each of the participants. So I think they are all pretty pleased. Whereas there are platforms with twenty-something professors, many of them got nothing... So we are kind of happy because everyone gets something. (Platform participant)

While the smaller platform was able to allocate funding for hiring a postdoc to each work package of the platform, due to the resource constraints, the larger platform instead opted for hiring a person to facilitate the applications for external funding and to bring together researchers and research teams from the large pool of platform participants on an ad hoc basis. In the case of the smaller platform, the benefits of participating in the platform can arguably be seen as more tangible, which may render the tensions concerning the allocation of resources less important. 


\section{Tensions Arising from Division of Labor and Disciplinary Relations}

Interdisciplinary collaboration is often conceptualized as a relation formed voluntarily between groups of equal status and authority, with equal control over how the research will pan out. Each participating group is thus able to craft a project in a way that benefits them not just in terms of financial resources, but also in terms of academic gain understood as theoretical progress within their own discipline and academic output in terms of publications. However, an interdisciplinary context also gives rise to a demand to adjust one's research to the aims or needs of the larger project which may be more important than theoretical progress within every participating group's discipline. Epistemic tensions emerge if an interdisciplinary collaboration does not provide potential epistemic benefits to each participating group or discipline but instead requires some to cater for or sacrifice to the needs of others. For instance in cases of scientific subordination one discipline's practices may be subordinated to another's epistemic goals at the cost of achieving its own (MacLeod 2018). Again, these epistemic tensions come with emotional reverberations for those who find themselves in subordinated positions.

In our case, the data revealed that tensions between disciplinary goals and objectives within the platforms were closely associated with perceptions of how fairly and evenly tasks were allocated, who was felt should be in control of allocating tasks and framing the research, and overall whether participants felt their fields were receiving appropriate status. In this section we elaborate on the nature and causes of such tensions in our platforms, many of which have an epistemic origin.

In Platform $C$ the relationship between the participating business scientist and the leader has exhibited tensions of this kind its entire course so far. As with Platform B, the platform is built around a scientific core of applied mathematicians specializing in inverse problems and chemists specializing in measuring water chemistry. This "natural scientific" group led the platform from its beginning, setting the research topic and framing the relevant problems. While the mathematical and chemical science investigations were already well formulated, the business science researchers found themselves in a position where they had to adjust their research to what the others were doing; in this case, applying business modeling methods to environmental monitoring data (emission data and the like). This has proved very difficult because the natural science researchers have had less interest in adapting their research to incorporate what the business scientists can offer. Since the natural science project in this platform is more or less sustainable (and integrated) as it is and since it was not constructed with a business perspective in mind, these researchers do not feel an onus to adapt their research goals and methods to better incorporate the business research.

This inflexibility on behalf of mathematicians and chemists is not just the result of the fact that the existing research of the natural scientific group is wellestablished. There is a degree to which the business researchers perceive this inflexibility as the result of attitudes towards the status of business science. As one business scientist reported early on, one of the engineering groups wanted to reserve most of the platform seed funding for itself on the basis that it perceived itself as requiring more funds. However, the university intervened to ensure that 
the money was allocated evenly and to avoid business researchers being assigned to the role of "Santa's little helper" as the same business researcher put it. Nonetheless this researcher found that attitudes towards business research as well as the priority and status of the engineering aspects of the project made it particularly hard for the person to identify a meaningful role in the platform. This excerpt from the business scientist expresses this problem particularly poignantly:

It's just that, for me, did not have any understanding, and even to this date, I don't know how the companies estimate their fucking emissions [laughing]: I don't know how, what, how reliable and where do these country-level emissions numbers come from. I do not understand how you get to know for example if it's reported that, okay, the role of traffic is so much and the role of agricultural is so much, so and so many percent of the emissions. I don't understand how they come up with these figures. So, in that sense I don't feel very comfortable in studying these and especially in trying to study the uncertainties related to them not being you know, having the deep understanding on where do they come from. (Platform participant, emphasis added)

The quote highlights an epistemic tension emerging from this researcher's concern for the reliability of the data the researcher has to work with in the project, and an emotional tension (discomfort) given this situation. Additionally, this researcher felt working against a strong expectation from the natural scientists that characterized business scientists as primarily data scientists without any relevant or important theoretical knowledge which could be contributed to the engineering science. In the person's own words,

That's what they expect. It's so that easy to expect that we do some kind of investment calculations or them, or market analyses, and so on. But they don't necessarily understand that that kind of stuff is done at the Bachelor level studies, and it's not academic research. (Platform participant, emphasis added).

Regardless it appears that business scientists in this platform took on the principal role of data scientists, even though these researchers characterize themselves primarily as mathematical modelers rather than data scientists. One consequence this had was to render their contribution vague, speculative or hypothetical, and outside their traditional modes of operating. Unlike the other groups, they would have to work much harder to find a plausible angle of investigation, for any benefit they could take from the platform, which was a source of dissatisfaction with the situation.

In Platform B the situation seems to exhibit similar circumstances and conditions which would give rise to tensions related to subordination or lack of clear participatory role and epistemic pay-off for the business researchers involved. The business researchers entered a platform characterized by an already established natural science and engineering group with well developed approaches and problems. However, both the engineers and business researchers have expressed 
mainly enthusiasm for their interactions, and as mentioned, the platform has proven successful. The engineering PI maintains that the relationship with the business researchers has played a significant role in the ability of his group to communicate with corporations and business-oriented funding agencies. Yet while this is a positive case, there are reasons to see similar subordinative aspects in the background, and the degree of interdisciplinarity is still relatively limited. The engineering PI has little engagement with the business scholarship. On the other hand, two business researchers in this platform we interviewed claim they have strong engineering backgrounds and do make it their task to engage with the engineering research in order to run their own research, suggesting a degree of imbalance in the effort and knowledge required for the collaboration. It also suggests the engineering researchers have something of a more instrumentalist attitude towards the role of the business research. Indeed, the initial primary role allocated to the business researchers was to collect data on customer feedback-exactly the kind of task dismissed by a business researcher from Platform $\mathrm{C}$ as mischaracterizing the depth and sophistication of industrial and engineering management. Nevertheless, it appears that the business researchers in Platform B have managed to direct this research in productive and meaningful ways for them, including the development of new business related concepts on gamification.

While we did not come across extensive issues, there is also some evidence of these tensions in Platform A. In one interview a sustainability scientist complained that all research questions were being framed from the perspective of chemical engineering and process optimization, while product design and other issues were not being taken into account. The nature of Platform $\mathrm{A}$ as a fund-raising instrument to individual projects rather than as a research unit of its own, however, makes it unlikely that tensions such as those related to scientific subordination would emerge at the platform level. Those tensions are more likely to arise in particular research projects that get funded through the platform.

\section{Tensions Relating to Scientific Output and Academic Careers}

A structural tension identified in previous research on tensions in interdisciplinary projects relates to scientific publishing and academic careers more generally. In the academic world where the majority of tenured positions is still located within disciplines, engagement in interdisciplinary research is often seen as risky business. In many disciplines, there are a few journals and academic publishers that count as the top publication venues in the field (Müller and Kaltenbrunner 2019). This creates a pressure for researchers to publish at those venues in order to obtain qualifications for tenured positions in their discipline. This goal becomes difficult or downright impossible to attain in interdisciplinary projects that require bargaining on where to publish the results insofar as top disciplinary journals are not viable options.

In the following quote, the tension relating to publishing in interdisciplinary collaboration is highlighted. The researcher reacts to the issue of advancing the academic careers of doctoral students and postdocs in their disciplinary field. 
We need to think about our own careers, and you need to establish the publication record for yourself, which would qualify you for any business school in the world. And for that kind of purposes, it's not necessarily good to publish in journals that you would probably publish if you worked in this interdisciplinary project on the platform. So you have to stay true to your own discipline. Otherwise you don't get any positions. Or at least you run a big risk of not getting any. (Platform participant, emphasis added)

In this example from Platform $\mathrm{C}$, the researcher stresses the need for focusing on publishing in one's own primary discipline or face the risks of not being able to secure an academic position. The researcher remarks that the high-ranking journals in the field prefer theoretical contributions while it is difficult to publish merely empirical contributions in those journals. Yet the research attributed to this work package in the platform even at its best is not capable of providing more than empirical results. These results can be published in some journals, but those publications do not count as academic merits if they are in wrong fields. This is a paramount example of tensions relating to both scientific subordination and academic publishing as it leaves business researchers without a realistic opportunity to benefit scientifically from the interdisciplinary interaction at the platform.

If the collaborators are not eager to publish in interdisciplinary journals that often have a lower ranking than the top disciplinary journals, one strategy is to alternate the role of the lead author and to write several co-authored articles to different disciplinary journals. This seems to have been the case in Platform B, where one engineering researcher stated that they have had numerous meetings with business researchers to develop publications directed toward the business science community. However, in order to be successful, this strategy requires that the participants collaborate on a more or less egalitarian basis and that there is mutual willingness "to understand and learn more from each other" as stated by a business researcher in the same Platform B. If this is not the case, then some co-authors may feel that they have been placed into a subservient role to bolster the careers of researchers from other disciplines. One option is also a publication of conference proceedings that brings together complementary perspectives on the same topic although leading academic publishers are increasingly reluctant to publish such volumes. Even so, the participants of Platform B have succeeded in publishing an interdisciplinary edited volume on their research topic.

Importantly, the problem with publishing interdisciplinary research has taken different forms in different platforms. Whereas the participants of Platform B have recognized and addressed this problem, it has been more at the stage of anticipation than in actual publication practices in Platform $\mathrm{C}$ because its participants have not yet published anything together as far as we know. Nevertheless, we hypothesize that the tension of scientific publishing has been aggravated by the platform structure, which requires researchers to collaborate with partners from the same university. Without this requirement, Platform $\mathrm{C}$ might have been able to involve or recruit less high-profile researchers - or even students - to conduct the kind of less demanding data collection tasks that were allocated to business researchers in that platform. 
Tensions relating to academic careers and scientific publishing attach to a more fundamental problem with academic incentive structure that favors disciplinary research and encourages avoiding risks such as interdisciplinary research where the risk of a scientific failure is high, and even if this risk can be avoided, academic risks to the participants remain. This tension involves an epistemic tension between developing expertise in one's own discipline and trying to learn new skills and competences in another discipline or disciplines. The emotional stakes of this tension can be high as can be seen from this quote from a researcher in Platform C:

There's not enough incentive to go outside your comfort zone and really try to do something with someone who is from a totally different field and with whom you don't have common understanding research. I guess that's it. And I think it's, well, maybe it's hard to incentivize that also. If you really love research and love your own areas of interest and are very hard working, devoted to that, then why should you... waste your time, or potentially waste your time in trying to learn something very, very new which probably, or where the risk of failure is very, very high. (Platform participant)

Talking about love for one's own areas of interest and about high risk of failure with trying to learn something new (here: interdisciplinarity), which implies anticipated negative emotions upon potential failure, also illustrates how incentives psychologically operate largely through emotions that in turn are notoriously difficult to modify, especially in a short term. The fact that organizational structures for interdisciplinary research often are temporary rather than long-standing reinforces incentives for engaging purely in disciplinary research. Platforms at BizTech are no exception with their 5-year funding period and no guarantee of continuation beyond 2020. It may be difficult to incentivize interdisciplinary research in such circumstances, especially for younger researchers who do not have a tenured position and whose principal aim is to get one. This situation gives rise to a tension between disciplinary and interdisciplinary orientation in research, which may be aggravated by the platform structure especially in those cases where the platform has brought together researchers who otherwise would not have engaged in collaboration with each other.

\section{Discussion}

The platform strategy is an attempt to incentivize interdisciplinary collaboration internally by changing internal funding structures. We only here examine 3 of the 6 platforms, so it has not been our goal in this article to give an overall evaluation of the platform strategy as a means of generating integrative interdisciplinary collaboration. However, while two of the cases have met, if not exceeded, the administration's funding goals, the cases send mixed signals on the ability of the strategy to achieve strong levels of interdisciplinarity. In only one platform, Platform B, do we see anything which might amount to interdisciplinary integration. Indeed, the assertion that epistemic, structural and emotional tensions manifest themselves in collaborations and confound attempts at integration is well-known. In our analysis we identified specific features of the platform strategy that induce such tensions at 
least in our cases. However, there are reasons to think that the platform strategy is structured in such a way that these tensions may be more severe and more likely to work against collaboration than in typical cases.

\section{The Organizational Context, Tensions and their Exacerbation}

The organizational format of the platforms at BizTech plays a crucial role when studying the tensions generated in interdisciplinary collaboration as it permeates the dynamics of interdisciplinary interaction. Based on our analysis, the platform format has three main implications for how research is organized: (1) the platforms need to involve researchers from the schools within BizTech, and (2) the platforms reshape the format of how research is organized and funded (3) the platform strategy adds a new layer of incentives on top of existing incentives. Each we believe have served to exacerbate those tensions which typically arise interdisciplinary interactions.

First, the requirement that the platforms have to include researchers from the different schools at BizTech shapes the composition of interdisciplinary collaborations. The requirement challenges the more traditional way of assembling research collaborations and consortia, in which participants are often selected across universities and where the rationale for participating is to a larger degree driven by common research interests and paradigms. Secondly, compelling collaboration among a small set of researchers is likely to accentuate epistemic tensions. For instance, funding policies which target application arguably already favour and reward engineering and technological sciences by giving them the status of "most fundable" research. Such status gives them a measure of authority to dictate and control collaborative funding applications in which they see themselves as critical. Requiring somewhat arbitrary collaboration within the university, rather than allowing researchers to discover collaborators "naturally" throughout the academic world on the basis of their expertise with respect to particular projects, forces researchers with less status or power to operate in contexts which they have little control over, and in which they will need to fight against biases they cannot easily change. On the other hand, more favored groups such as engineers who have a prominent role within the system do not have any special incentive to adapt their own practices. As such the obligation to adapt mostly falls on the party with less currency within the system, who then require a significant investment of time adapting their methods and practices with an uncertain reward for doing so. In the case of Platform B, the PI has been extraordinarily open to collaboration, which has alleviated some of the risks, and in this case it was clear to the person there was a payoff in terms of an opportunity to acquire funding easily with minimum effort required on the engineering part. Similarly, the business researchers clearly perceived their funding opportunities in this platform. In most situations, however, this is unlikely to be the case. In the case of Platform $\mathrm{C}$, the circumstances gave the business science participants very little or no control over the direction of their research accentuating the tensions for them between committing to the project and to their disciplinary goals. Such tensions are likely to undermine the motivations researchers might have to persist in an interdisciplinary collaboration. 
Second, the platform structure challenges the traditional format of how research is conducted and organized. It does so by shifting the focus away from individual research projects to broader platforms as well as from individual research groups and to larger sets of groups. This changes how responsibilities and resources are shared among the researchers as well as whose research goals and aims are prioritized. As discussed in Section 4.1, the platform format alters the allocation of funding, where the research groups need to negotiate how money is distributed between them. In Platform A, the largest platform in our study, this gave rise to considerable tensions, as all professors were not able to get their "share" of the platform funding. In the other studied platforms, due to the smaller amount of research groups involved, these tensions were not identified. From a research funding point of view, it seems that the platform structure has more significant implications the bigger the number of participants is. By shaping the traditional format of how research is organized, the platform structure also has implications for the tensions pertaining to the division of labor (Section 4.2). By moving the authority away from single research groups, the PI's control of which types of research questions are to be pursued and which methods will be used, for example, becomes weaker. To illustrate further how the platform makes the researchers rethink the ways in which research is conducted and organized and the challenges this generates, when asked about the difference between traditional projects and the platform, a researcher from Platform A responded as follows:

So, all the other projects that we are working on, they are smaller, and we have specific questions. We have a problem that we need to solve. And, on this platform, there is no such problem, currently, and this is the reason why there is no activity for the teams. The platform is kind of organized to solve a problem. But, there is no specific problem, so that's why it seems that the platform is not functioning. (Platform participant)

Interestingly, the same researcher agreed that the specific problems studied in individual research groups of the platform thematically fall under the research questions described in the platform's research plan. The following quote highlights the difficulties with perceiving platforms as a meaningful level or type of organization from the perspective of individual groups and their traditional format of conducting research.

It is exactly overlapping. So, we are doing precisely these kinds of things all the time. But, it's not done via the platform, so the platform does not bring the added value.

Additionally, by removing funding and then putting researchers in the position of having to get it back by a competitive application procedure, the platform strategy foregrounds financial issues and negotiations in place of seeking out meaningful grounds upon which to collaborate up front. And it creates higher stakes and urgency for these financial decisions. Such tensions surrounding who gets what and the allocation of resources generally take an immediate and often formative role with respect to any researcher's willingness to engage with or stay 
in a platform, as we saw in case $\mathrm{A}$ and case $\mathrm{C}$, at the cost of effective collaboration. Indeed, researchers have a strong incentive to engage in platforms primarily as a means to ensure basic funding rather than because a platform topic of investigation necessarily fits well their research approaches in any substantive way. In such a context, platforms risk being treated more as frameworks for resource distribution under the guise of a central topic of investigation than as frameworks for building deeper interdisciplinary collaborations, particularly if such collaboration might result in something other than an even redistribution.

Finally we can attribute the exacerbation of pre-existing interdisciplinary tensions, partially at least, to the fact that the strategy operates by creating a new strong layer of incentives without removing or changing existing ones. These two layers of incentives are not necessarily consistent with one another. These conflicting incentives create costs to researchers for choosing one action over another, and this conflict is the origin of some of the tensions they experience. For instance, the platform strategy develops a strong incentive for interaction and collaboration on project ideas and grant proposals in order to receive external research funds, and while in cases the incentives for doing so might align well with the ordinary incentives of research to produce solid disciplinary work (as in Platform B), this is not always the case as mentioned resulting in the conflicting incentives experienced in Platform C. Moreover, it is not likely that temporary organizational reforms such as the platforms are capable of influencing researchers' incentives formed and rooted during their careers spent in academic organizations governed by disciplinary research. Indeed, the need to produce good disciplinary work still remains essential, and factors into decision-making on tenure and promotion even by university administrators. While these aspects of academic work are ordinarily in tension in any interdisciplinary collaboration, the platform strategy adds strong financial incentives to collaborate which ramps up such a tension, even more so when one considers that somewhat arbitrary collaborations that are projected to be relatively short-term are likely to be harder and involve greater conceptual distance than those developed or discovered more organically.

An exacerbation of the interdisciplinary tensions suggests that trying to force interdisciplinarity though such structural innovations can in certain circumstances heighten the obstacles to an integrative interdisciplinarity, if the landscape of incentives is not at the same time adapted to suit the policy. Of course the results of implementing a policy with different incentives on top of existing ones may lack predictiveness without testing the policy beforehand. In this case reporting on these tensions should help revise and adapt the policy to better take into account different incentives and how researchers may respond to them.

\section{Unclear Status of Interdisciplinary Policy Goals}

However, the consequences of exacerbating tensions may be compounded by a more basic problem in the way the platform strategy is formulated, namely, whether such a platform strategy aims chiefly at optimizing the ability of researchers to gain external funding, or whether its primary goal is to foster collaborative interdisciplinary 
interactions as a means to solve contemporary challenges. When it comes to optimizing funding opportunities, the platforms can provide researchers advantages such as (i) a wider space of funding opportunities they would not have otherwise had, by virtue of their different backgrounds, (ii) means for pooling corporate relationships to strengthen funding applications, and (iii) means for creating dedicated collectives specialized in specific problems and issues useful for funding applications. Gaining these mutual advantages does not directly require integrative interdisciplinarity. In fact, making use of these advantages is consistent with researchers attaching themselves to an already successful laboratory, and providing this lab modest input in order to increase their own chances of getting both internal and external funds. While this may bring in more funding, pooling resources in these ways serves to reinforce the epistemic goals and values of the central laboratory, rather than promote balanced communication and integration. The result is the emergence of domains of specialization, but mostly around already well-funded researchers and their goals, further increasing their status and authority. Even in the case of Platform $\mathrm{B}$ the engineers principally see the relationship with the business school as somewhat transactional and feel no particular need to adjust their practices or approaches, or even fully understand what the business scholarship in the platform achieves. Arguably, the business school participants see it likewise as an opportunity for recovering their internal funding with relatively minimal effort by applying familiar data-collection techniques to a particular case. The result has been arguably a very effective collaborative pooling of resources, and leveraging of a wider space of available funding opportunities, yet without deep interdisciplinary engagement. Indeed, the overall strategy of the network-type Platform A might be considered as something akin to this.

Our analysis suggests then that researchers tend to identify the principal goal of the platform strategy with funding acquisition rather than with interdisciplinarity. And while deep levels of interdisciplinarity might lead to very competitive funding applications, plenty of advantages can be gained from much lighter forms of interactions and resource pooling without engaging in deeper tension-bound and difficult integration. As such an issue with the platform strategy or at least its current implementation is that the independent importance of the goal of interdisciplinarity, and its requirements, are not clearly articulated, allowing researchers to essentially avoid interdisciplinarity (see Lindvig and Hillersdal 2019).

\section{Conclusions}

Despite what is seen as a pressing need for interdisciplinarity, stimulating it through specific funding and other incentives remains difficult. In this article, we have studied a small technical university in a Nordic country, which has adopted the novel strategy of attempting to restructure university research around interdisciplinary collaboration through targeted allocation of its own research funds. Our goal here has been to focus on the kinds of tensions amongst collaborators such a top-down, strategy-led initiative can create, thus acting as obstacles to achieving integrative forms of interdisciplinarity. We identified three sources of tensions: (1) in the allocation of 
platform resources, (2) in the division of labor and disciplinary relations, (3) scientific output and academic careers. In addition, our analysis highlights that the particular structure of the research platforms exacerbates the identified tensions. The platform format requires inclusion of researchers from at least two schools within the same university and the way in which the platforms reshape the taken-forgranted form of organizing research in contemporary universities.

We suggest the way the strategy is formulated means such tensions tend to be exacerbated over and above those usually encountered in interdisciplinary contexts, to the detriment of achieving substantial interdisciplinary interaction. At least in our three cases the level of integration achieved is limited as a result. As a result, our article highlights the organizational challenges of implementing novel strategies to purposely induce interdisciplinary research within universities. By adding an additional organizational layer within the university with its own incentives, some of which are inconsistent with existing ones, and strategic objectives that challenge the traditional way of conducting research, researchers are forced to balance between the opportunity of forming new interdisciplinary research partnerships and continuing with business-as-usual. If such a strategy is to succeed more thought needs to be given on how such new levels of organization could be aligned better with existing organization and current incentives both within and across universities. Better insight on how to do so could be gained through comparison of similar strategies being currently put in place in different university systems. Such future research would also help us gain more insight into how local practices and institutions affect how such strategies play out.

Authors' Contributions All authors contributed equally.

Funding Open Access funding provided by University of Helsinki including Helsinki University Central Hospital. Open Access funding provided by University of Helsinki including Helsinki University Central Hospital. Academy of Finland Project No 298049.

\section{Compliance with Ethical Standards}

Conflict of interest None.

Availability of Data and Material Available upon request.

Open Access This article is licensed under a Creative Commons Attribution 4.0 International License, which permits use, sharing, adaptation, distribution and reproduction in any medium or format, as long as you give appropriate credit to the original author(s) and the source, provide a link to the Creative Commons licence, and indicate if changes were made. The images or other third party material in this article are included in the article's Creative Commons licence, unless indicated otherwise in a credit line to the material. If material is not included in the article's Creative Commons licence and your intended use is not permitted by statutory regulation or exceeds the permitted use, you will need to obtain permission directly from the copyright holder. To view a copy of this licence, visit http://creativecommons.org/licen ses/by/4.0/. 


\section{References}

Andersen, Hanne. 2016. Collaboration, interdisciplinarity, and the epistemology of contemporary science. Studies in History and Philosophy of Science 56: 1-10.

Becher, Tony, and Paul Trowler. 2001. Academic Tribes and Territories. Buckingham: The Society for Research into Higher Education \& Open University Press.

Boardman, Craig, and Barry Bozeman. 2007. Role strain in university research centers. The Journal of Higher Education 78(4): 430-463.

Boardman, P. Craig, and Elizabeth A. Corley. 2008. University research centers and the composition of research collaborations. Research Policy 37(5): 900-913.

Brint, Steven. 2005. Creating the future: 'New directions' in American research universities. Minerva 43(1): 23-50.

Buanes, Arild, and Svein Jentoft. 2009. Building bridges: Institutional perspectives on interdisciplinarity. Futures 41(7): 446-454.

Callard, Felicity, and Des Fitzgerald. 2016. Rethinking interdisciplinarity across the social sciences and neurosciences. Basingstoke: Palgrave Macmillan.

Choi, Hyungsub, and Brit Shields. 2015. A place for materials science: Laboratory buildings and interdisciplinary research at the University of Pennsylvania. Minerva 53(1): 21-42.

Collins, Randall. 1998. The Sociology of Philosophies. Cambridge, MA: Harvard University Press.

Franssen, Thomas, Wout Scholten, Laurens K. Hessels, and Sarah de Rijcke. 2018. The drawbacks of project funding for epistemic innovation: Comparing institutional affordances and constraints of different types of research funding. Minerva 56(1): 11-33.

Grüne-Yanoff, Till. 2016. Interdisciplinary success without integration. European Journal for Philosophy of Science 6(3): 343-360.

Hackett, Edward J. 2005. Essential tensions. Identity, control, and risk in research. Social Studies of Science 35(5): 787-826.

Holley, Karri. 2017. Administering interdisciplinary programs. In The Oxford Handbook of Interdisciplinarity, eds. Robert Frodeman, Julie Thompson Klein, and Roberto Carlos Dos Santos Pacheco, 530-543. Oxford: Oxford University Press.

Hsieh, Hsiu-Fang, and Sarah E. Shannon. 2005. Three approaches to qualitative content analysis. Qualitative Health Research 15(9): 1277-1288.

Huutoniemi, Katri, Julie Thompson Klein, Henrik Bruun, and Janne Hukkinen. 2009. Analyzing interdisciplinarity: Typology and indicators. Research Policy 39(1): 79-88.

Jacobs, Jerry A., and Scott Frickel. 2009. Interdisciplinarity: A critical assessment. Annual Review of Sociology 35(1): 43-65.

Kuhn, Thomas S. 1970. The Structure of Scientific Revolutions. Chicago, IL: The University of Chicago Press.

Leahey, Erin, Christine M. Beckman, and Taryn L. Stanko. 2017. Prominent but less productive: The impact of interdisciplinarity on scientists' research. Administrative Science Quarterly 62(1): 105-139.

Lindvig, Katrine, and Line Hillersdal. 2019. Strategically unclear? Organising interdisciplinarity in an excellence programme of interdisciplinary research in Denmark. Minerva 57(1): 23-46.

Lyall, Catherine, Ann Bruce, Wendy Marsden, and Laura Meagher. 2013. The role of funding agencies in creating interdisciplinary knowledge. Science and Public Policy 40(1): 62-71.

Mansilla, Veronica Boix, Michèle Lamont, and Kyoko Sato. 2016. Shared cognitive-emotional-interactional platforms: Markers and conditions for successful interdisciplinary collaborations. Science, Technology, \& Human Values 41(4): 571-612.

MacLeod, Miles. 2018. Scientific Subordination, Molecular Biology and Systems Biology. In Scientific Imperialism: Exploring the Boundaries of Interdisciplinarity, eds. Uskali Mäki, Adrian Walsh, and Manuela Fernández Pinto. London, New York: Routledge.

MacLeod, Miles, and Michiru Nagatsu. 2018. What does interdisciplinarity look like in practice: Mapping interdisciplinarity and its limits in the environmental sciences. Studies in History and Philosophy of Science, Part A 67: 74-84.

Müller, Ruth, and Wolfgang Kaltenbrunner. 2019. Re-disciplining academic careers? Interdisciplinary practice and career development in a Swedish environmental sciences research center. Minerva 57(4): 479-499. 
Mäkinen, Elina I., Eliza D. Evans, and Daniel A. McFarland. 2020. The patterning of collaborative behavior and knowledge culminations in interdisciplinary research centers. Minerva 58(1): 71-95.

National Academy of Sciences, National Academy of Engineering, and Institute of Medicine. 2005. Facilitating Interdisciplinary Research. Washington, DC: The National Academies Press.

Parker, John, and Beatrice Crona. 2012. On being all things to all people: Boundary organizations and the contemporary research university. Social Studies of Science 42(2): 262-289.

Parker, John N., and Edward J. Hackett. 2012. Hot spots and hot moments in scientific collaborations and social movements. American Sociological Review 77: 21-44.

Pohl, Christian, Bernhard Truffer, and Gertrude Hirsch-Hadorn. 2017. Addressing wicked problems through transdisciplinary research. In The Oxford Handbook of Interdisciplinarity, eds. Robert Frodeman, Julie Thompson Klein, and Roberto Carlos Dos Santos Pachecho, 319-331. Oxford: Oxford University Press.

Rhoten, Diana, and Andrew Parker. 2004. Risks and rewards of an interdisciplinary research path. Science 306(5704): 2046.

Salmela, Mikko, and Uskali Mäki. 2018. Disciplinary emotions in imperialistic interdisciplinarity. In Scientific Imperialism: Exploring the Boundaries of Interdisciplinarity, eds. Uskali Mäki, Adrian Walsh, and Manuela Fernández Pinto, 31-50. London, New York: Routledge.

Soini, Katriina, Alexandra Jurgilevich, Janna Pietikäinen, and Kaisa Korhonen-Kurki. 2018. Universities responding to the call for sustainability: A typology of sustainability centres. Journal of Cleaner Production 170: 1423-1432.

Townsend, Tony, John Pisapia, and Jamila Razzaq. 2015. Fostering interdisciplinary research in universities: A case study of leadership, alignment and support. Studies in Higher Education 40(4): 658-675.

Turner, V. Kelly, Karina Benassaiah, Scott Warren, and David Iwaniec. 2015. Essential tensions in interdisciplinary scholarship: Navigating challenges in affect, epistemologies, and structure in environment-society research centers. Higher Education 70: 649-665.

Wright, Claire, and Simon Ville. 2017. Visualising the interdisciplinary research field: The life cycle of economic history in Australia. Minerva 55(3): 321-340.

Publisher's Note Springer Nature remains neutral with regard to jurisdictional claims in published maps and institutional affiliations. 